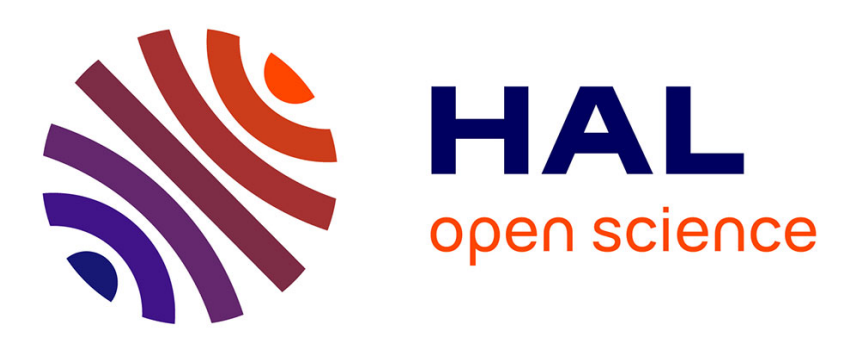

\title{
Shockwave Generation and Radiation from an UHBR Engine with Flow Distortion Using a CFD/CAA Chaining Strategy
}

\author{
Majd Daroukh, Cyril Polacsek, Alain Chelius
}

\section{- To cite this version:}

Majd Daroukh, Cyril Polacsek, Alain Chelius. Shockwave Generation and Radiation from an UHBR Engine with Flow Distortion Using a CFD/CAA Chaining Strategy. 25th AIAA/CEAS Aeroacoustics Conference, May 2019, DELFT, Netherlands. 10.2514/6.2019-2605 . hal-02196620

\section{HAL Id: hal-02196620 \\ https://hal.science/hal-02196620}

Submitted on 29 Jul 2019

HAL is a multi-disciplinary open access archive for the deposit and dissemination of scientific research documents, whether they are published or not. The documents may come from teaching and research institutions in France or abroad, or from public or private research centers.
L'archive ouverte pluridisciplinaire $\mathbf{H A L}$, est destinée au dépôt et à la diffusion de documents scientifiques de niveau recherche, publiés ou non, émanant des établissements d'enseignement et de recherche français ou étrangers, des laboratoires publics ou privés. 
archives-ouvertes

\section{Shockwave Generation and Radiation from an UHBR Engine with Flow Distortion Using a CFD/CAA Chaining Strategy}

Majd Daroukh, Cyril Polacsek, Alain Chelius

\section{- To cite this version:}

Majd Daroukh, Cyril Polacsek, Alain Chelius. Shockwave Generation and Radiation from an UHBR Engine with Flow Distortion Using a CFD/CAA Chaining Strategy. 25th AIAA/CEAS Aeroacoustics Conference, May 2019, DELFT, Netherlands. 10.2514/6.2019-2605 . hal-02196620

\section{HAL Id: hal-02196620 \\ https://hal.archives-ouvertes.fr/hal-02196620}

Submitted on 29 Jul 2019

HAL is a multi-disciplinary open access archive for the deposit and dissemination of scientific research documents, whether they are published or not. The documents may come from teaching and research institutions in France or abroad, or from public or private research centers.
L'archive ouverte pluridisciplinaire HAL, est destinée au dépôt et à la diffusion de documents scientifiques de niveau recherche, publiés ou non, émanant des établissements d'enseignement et de recherche français ou étrangers, des laboratoires publics ou privés. 


\title{
Shockwave Generation and Radiation from an UHBR Engine with Flow Distortion using a CFD/CAA Chaining Strategy
}

\author{
M. Daroukh*, C. Polacsek ${ }^{\dagger}$, and A. Chelius ${ }^{\ddagger}$ \\ DAAA, ONERA, Université Paris Saclay \\ F-92322 Châtillon - France
}

\begin{abstract}
This paper presents aeroacoustic investigations on a full-scale Ultra High Bypass Ratio (UHBR) engine with inflow distortion at transonic conditions. Computational Fluid Dynamics (CFD) simulations are first realized to compute the shocks in the vicinity of the fan. The shocks are then radiated outside of the nacelle thanks to Computational AeroAcoustics (CAA) simulations. The same solver is used for both CFD and CAA simulations and the chaining is done by injecting the shocks in terms of usual conservative variables using a non-reflecting boundary condition. The CAA solver is based on the non-linearized Euler equations which allows to define the CFD/CAA interface close to the fan where the propagation of shocks is highly non-linear. Both shock generation and shock propagation mechanisms are investigated and the effects of inflow distortion are highlighted by comparison with a baseline case without distortion. It is shown that the distortion, characterized by an acceleration of the flow at the bottom of the nacelle, is responsible for a modification of the shock amplitudes that depends on the circumferential position. Thus, azimuthal modes appear in addition to the rotor-locked mode present without distortion. The near-field radiation is also highly impacted with most of the noise being directed towards the sky. This is due to the blockage of shocks by a supersonic flow region in the bottom of the nacelle. The radiation is in addition highly heterogeneous in the other directions because of the various angles of the shocks that leave the nacelle.
\end{abstract}

\section{Introduction}

The reduction of fuel consumption has driven the evolution of aeroengines towards higher bypass ratio architectures. The most recent ones - called Ultra High Bypass Ratio (UHBR) - are equipped with very short asymmetric intakes which cannot make the entering flow uniform in the azimuthal direction. This flow heterogeneity (or distortion) is further amplified at operating conditions with non-zero angle of attack. This is typically the case during landing or take-off operations (angle of attack around $10^{\circ}-15^{\circ}$ ) where airport neighbours are the most exposed to noise nuisance. Several recent studies have therefore focused on the impact of distortion on the noise emitted by turbofan engines [1-8]. They have shown that the tone noise characteristics can be significantly modified by: (a) introducing new acoustic sources caused by the distortion/fan blades interaction [3-5], (b) modifying the conventional fan-blade wakes/Outlet Guide Vanes (OGVs) interaction [3-5, 8], and (c) modifying the generation and propagation of fan-blade shocks at transonic speeds [1-3, 5-7].

The present paper focuses on that last point. Shockwave generation and radiation can be estimated using a Computational Fluid Dynamics (CFD) solver in a one-simulation approach as proposed by recent studies [2, 6]. However, the associated computational cost is very high and the radiation of acoustic waves outside of the nacelle cannot be correctly captured over an important distance. Most of the studies [1, 3, 7] are therefore based on a two-step methodology where the CFD solution is chained to a Computational AeroAcoustics (CAA) solver to propagate and radiate the shocks. The latter methodology is chosen here using the CFD/CAA chaining strategy developed by Thisse et al. [9, 10]. The originality of this method is that the CAA part is done by solving the non-linearized Euler equations (while the linearized ones are often solved when dealing with CAA). This choice allows to study separately the shock generation and the shock propagation mechanisms by defining the CFD/CAA chaining interface very close to the fan where the propagation of shocks is highly non-linear. The effects of inlet or liner design in the presence of a realistic source could therefore be easily investigated in the future with this methodology by repeating only the CAA simulation (as long as the coupling effects on shock generation can be discarded).

\footnotetext{
*Research Engineer, Department of Aerodynamics, Aeroelasticity, and Aeroacoustics, majd.daroukh@onera.fr.

${ }^{\dagger}$ Research Engineer, Department of Aerodynamics, Aeroelasticity, and Aeroacoustics, cyril.polacsek@onera.fr.

†esearch Engineer, Department of Aerodynamics, Aeroelasticity, and Aeroacoustics, alain.chelius@onera.fr.
} 
This study is carried out in the framework of a Clean Sky 2 European project (ASPIRE) for which a full-scale UHBR engine model has been designed. Since no stagger variation is included between the blades, the acoustic waves radiate at the Blade Passing Frequency (BPF) and its harmonics only (i.e. there is no multiple pure tone [11]). The effects of distortion on both shock generation and shock propagation are highlighted by comparing the results with a baseline case with a clean inflow (zero angle of attack).

The paper is structured as follows:

- Sec. III gives a presentation of the turbofan model;

- Sec. III describes the numerical strategy including the CFD/CAA chaining;

- Sec. IV presents the effects of distortion on shock generation;

- Sec. V presents the effects of distortion on shock radiation;

- and finally Sec. VI adresses the main conclusions.

\section{ASPIRE Turbofan Model and Operating Conditions}

The ASPIRE fan stage includes an asymmetric intake with a small drop, $B=16$ rotor blades, and $V=36$ OGVs. The target bypass ratio is equal to 16 and the in-flight minimum thrust was chosen to be representative of a modern mid-sized passenger aircraft, with a nacelle radius around 1 meter. In order to simplify the numerical set-up and to reduce the computational cost, the drop is neglected and both simulations are performed using an axisymmetric intake shown in Fig. 1. It is not supposed to have an important influence on shock generation and propagation since the distortion is mainly caused by the flow incidence. Transonic operating conditions are investigated with and without distortion as summarized in Table 1 .

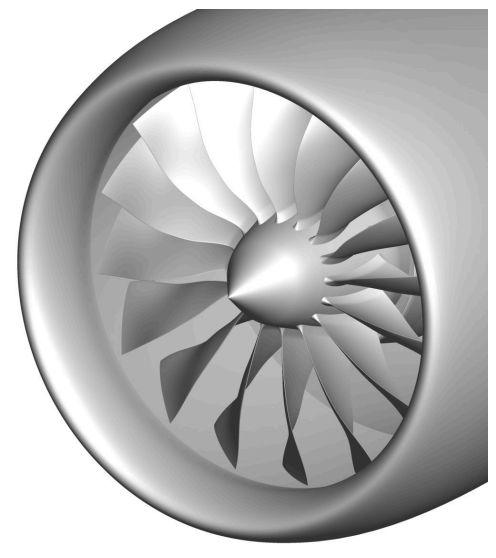

(a) Front view.

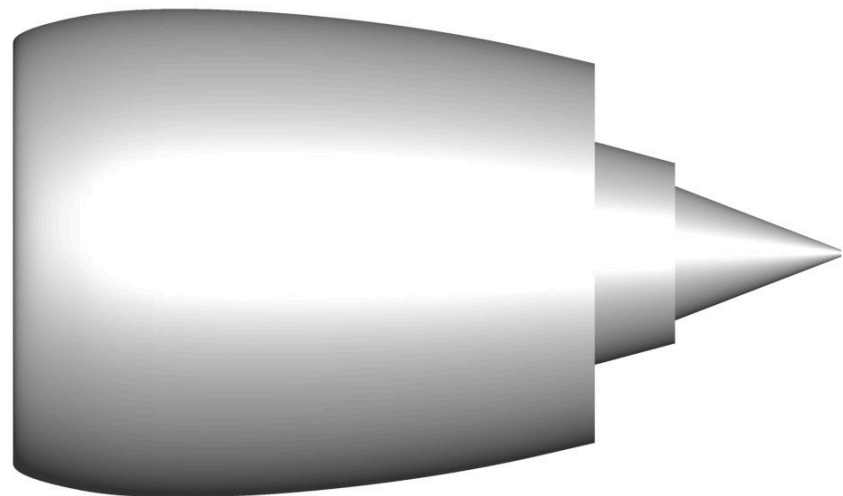

(b) Side view.

Fig. 1 ASPIRE turbofan model.

Table 1 Operating conditions with/without flow distortion.

\begin{tabular}{ccc}
\hline & Baseline & Distortion \\
\hline Fan rotation speed (vs. nominal regime) & $108 \%$ & $108 \%$ \\
Flight Mach number & 0.27 & 0.27 \\
Relative tip Mach number & 1.14 & 1.14 \\
Angle of attack & $0^{\circ}$ & $15^{\circ}$ \\
\hline
\end{tabular}




\section{Numerical Strategy}

\section{A. CFD Simulation}

The first step of the numerical methodology proposed here is the computation of fan-blade shocks thanks to a CFD simulation. It is done using the ONERA's CFD solver $e l s A$ which is based on a cell-centered finite volume approach on a structured multi-block grid [12]. The computational domains for baseline and distortion cases shown in Fig. 22 are restricted to the fan and the nacelle is approximated by a duct with suited inlet and outlet boundary conditions to reach the target values for inlet, bypass, and core mass flow (not given for confidentiality reasons).

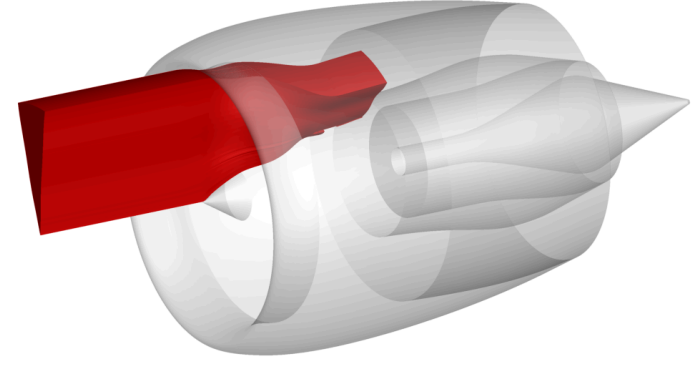

(a) Baseline case - CFD domain in red.

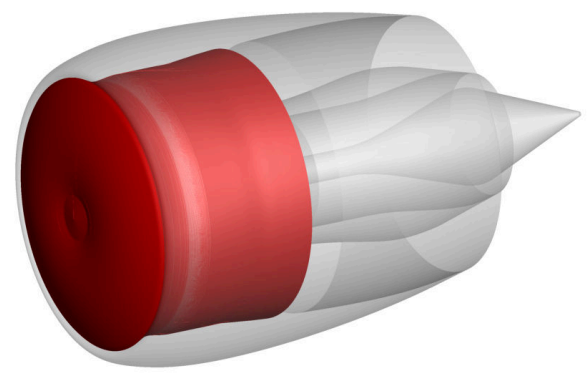

(c) Distortion case - CFD domain in red.

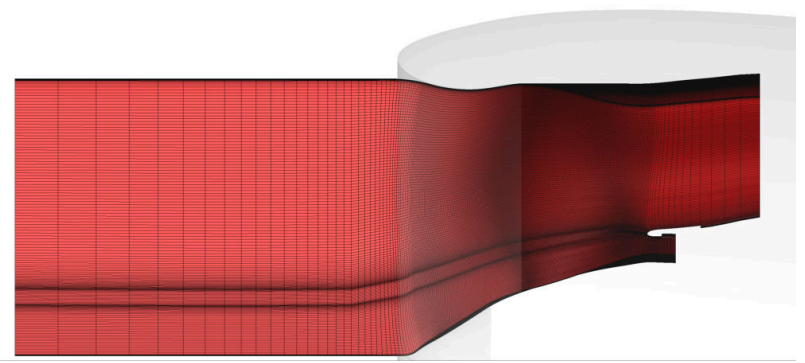

(b) Baseline case - Grid section view.

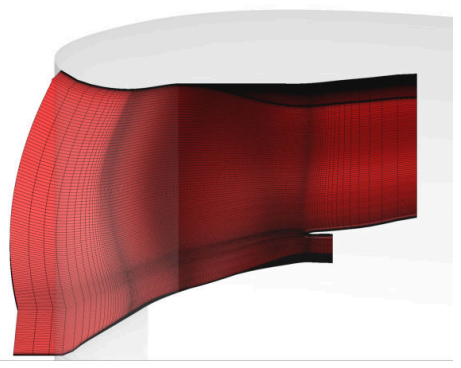

(d) Distortion case - Grid section view.

Fig. 2 CFD domains and grid section views.

For the baseline case, the Reynolds-Averaged Navier-Stokes (RANS) equations are solved in the rotating frame (the shocks are stationnary in the rotating frame when there is no distortion). The turbulent quantities are determined using $k-\epsilon$ two-equation model, the spatial discretization is done with Roe scheme with Van Albada limiter and the temporal one is based on a first-order backward Euler scheme. A single channel grid of about 15 million points is designed to capture the shock correctly around the fan blade (see Figs. 2a and 2b). The mesh is extended in the upstream direction to accurately propagate the $\mathrm{N}$-waves up to the exit section (useful for further comparison between CFD and CAA propagation). A stretching is then added in the upstream block to limit numerical reflections at inlet boundary. The simulation is run on 69 cores and costs about 3000 CPUh in total.

For the distortion case, the unsteady RANS (uRANS) equations need to be solved since the shocks are no longer stationnary in the rotating frame. As for the baseline case, $k-\epsilon$ turbulence model and Roe spatial scheme with Van Albada limiter are used. However, the time integration is based on a second-order Gear algorithm with 3600 time steps per fan rotation. A full-annulus mesh grid of about 208 million points is designed to account for distortion (see Figs. 2c and 2d). Inflow distortion map at the nacelle entrance has been extracted from an uRANS computation of the whole nacelle-fan configuration performed by NLR [7], associated partner of ASPIRE project, and has been kindly provided to ONERA. This map is used as the inlet boundary condition and allows to restrict the uRANS computation with distortion to the in-duct domain. The mesh cannot be extended in the upstream direction as done for the baseline case and the stretching is made closer to the fan. Finally, to prevent from inaccuracies of the sliding mesh approach, the map is injected directly in the rotating frame by being rotated at each time step in the opposite direction of the fan rotation (possible because of the use of an axisymmetric intake). This simulation is done over 448 cores. Six revolutions in total 
are needed to converge the unsteady phenomena. The first three revolutions are done on a coarse mesh (1 point over 2 in each direction) and costs about 15,000 CPUh. Three more revolutions are then made on the fine mesh for a total of 65,000 CPUh.

The axial velocity contours obtained from the distortion map are shown in Fig. 3a and some azimuthal profiles extracted at different blade heights are represented in Fig. 3b(each profile is normalized by its mean value). Higher velocities are reached at the bottom of the nacelle $\left(\theta=-90^{\circ}\right)$ because of the flow acceleration on the upper lip which is increased by the flow incidence. The azimuthal Fourier components have been computed in Fig. 3c from the azimuthal profiles and show a largely dominant spatial harmonic with circumferential order equal to 1 at all radial stations.

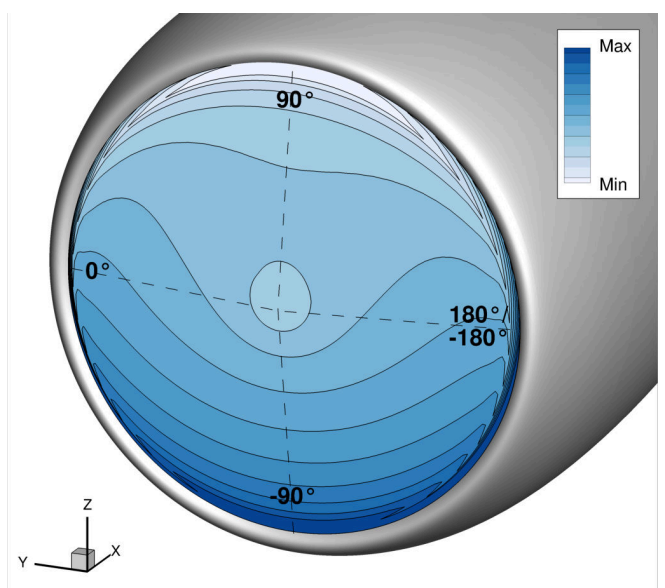

(a) Axial velocity contours.

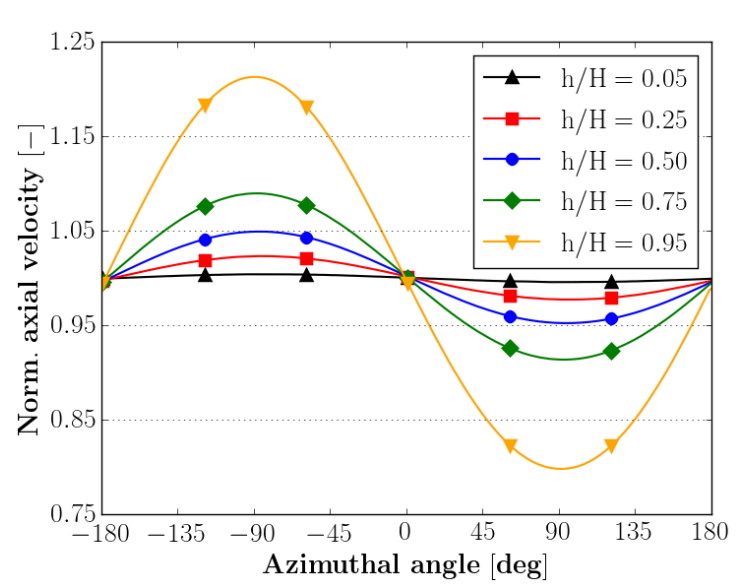

(b) Azimuthal profiles at different blade heights.

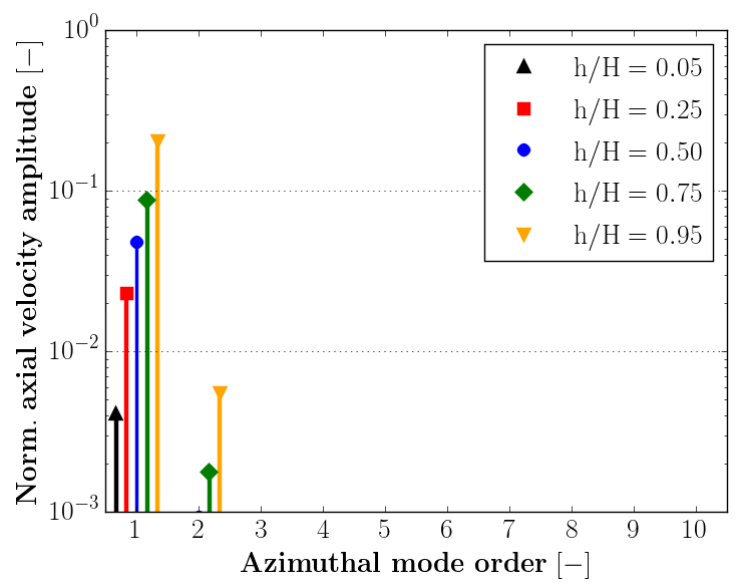

(c) Spatial harmonics at different blade heights.

Fig. 3 Inflow distortion map.

\section{B. CAA Simulation}

The second step of the proposed methodology is the propagation of shocks using a CAA solver. The elsA solver is used again by turning the RANS/uRANS mode into full Euler mode (non-linearized equations), viscous effects being negligible for shock propagation. The CFD/CAA chaining method developed by Thisse et al. [9, 10] is used. The shock signature in the vicinity of the fan is extracted from the CFD and is injected in the CAA domain in terms of usual conservative variables using the non-reflecting boundary condition based on 1D characteristic equations. A specific treatment is applied for converting the input data from the rotating frame (CFD solution) to the fixed frame (CAA frame).

The CAA domain is shown in Fig. 4a for a single channel. The computation is made on this single channel for the baseline case, with periodic conditions on azimuthal boundaries. For the distortion case, the same mesh is used and the 
domain is only duplicated over $360^{\circ}$. A coarsen grid section view ( 1 over 4 points) is given in Fig. $4 \mathrm{~b}$ and shows the refined region. The grid is designed to propagate acoustic waves with at least 30 points per wavelength up to BPF5 in the inlet region. A stretching is then made to avoid reflections on far-field boundaries. In total, the single channel grid totalizes 23 million points and the full-annulus one about 341 million points. Non-reflective boundary conditions are chosen at all fluid boundaries, Roe spatial scheme with Van Albada limiter is used and time integration is based on a second-order Gear algorithm with 3600 time steps per fan rotation. For both simulations, four and half rotations are done to converge the acoustic fluctuations. The simulation is run over 128 cores and costs about 6000 CPUh for the baseline case. For the distortion case, 448 cores are used and the simulation costs about 60,000 CPUh.

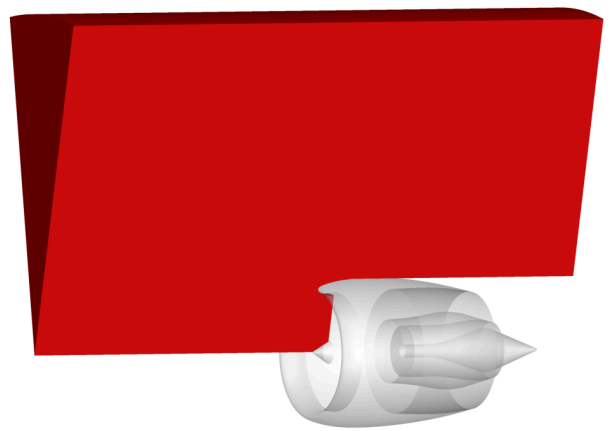

(a) CAA domain in red (single channel view).

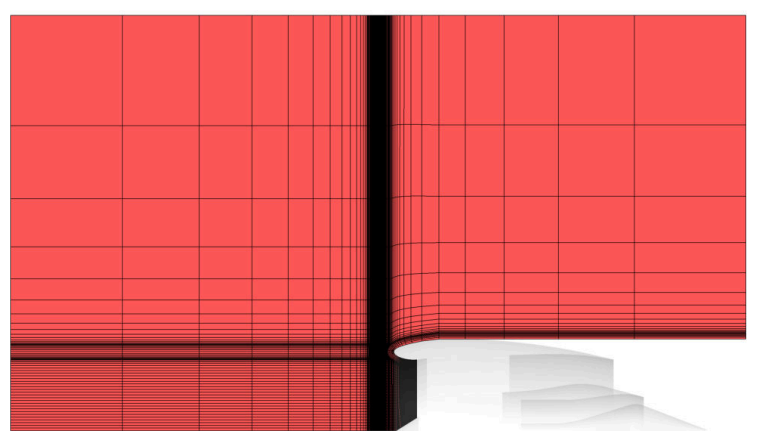

(b) Grid section view (1 over 4 points).

Fig. 4 CAA domain and grid section view.

The behaviour of the CFD/CAA chaining method is checked for the baseline case in Fig. 5, where the density field extracted from the CFD simulation and injected in the CAA simulation at a given iteration (Fig. 5a) is compared with the one extracted from the first cells of the CAA simulation at the same iteration (Fig. 5b). A very good agreement is obtained, which gives credit to the chosen strategy.

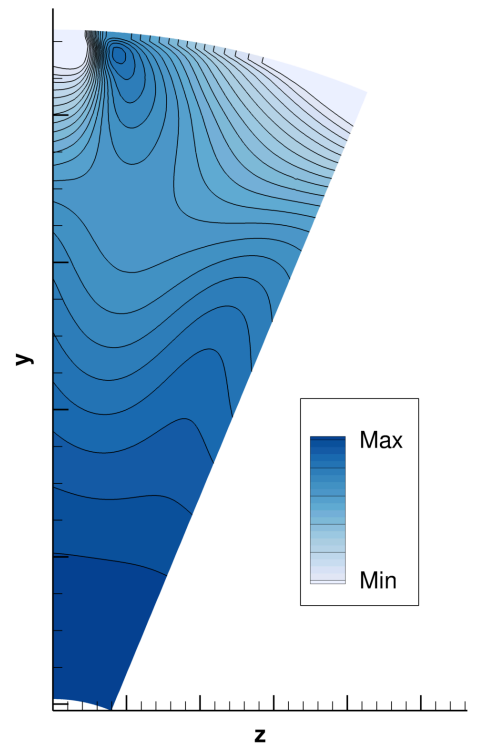

(a) Data extracted from the CFD simulation and injected in the CAA simulation.

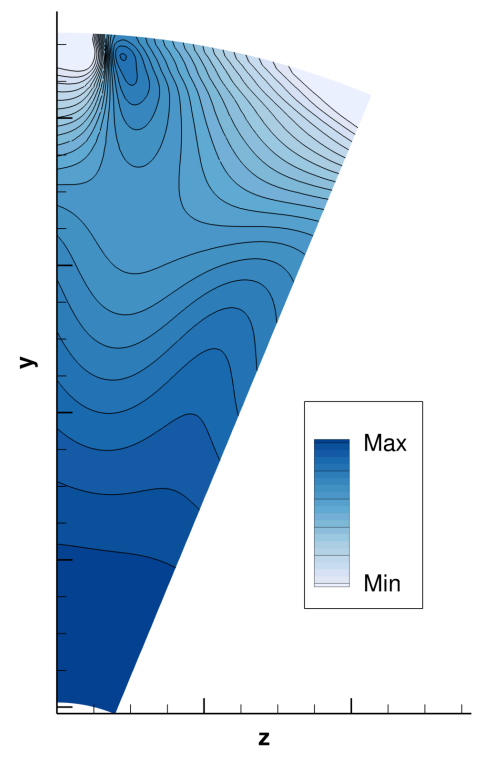

(b) Data extracted from the first cells of the CAA simulation.

Fig. 5 Density contours on the CFD/CAA chaining interface. 


\section{Effects of Flow Distortion on Shockwave Generation}

\section{A. Flow Description around Fan-Blades}

The focus is first put on the shock generation mechanism by analyzing the results of CFD simulations in the vicinity of fan blades. Contour plots of relative Mach number extracted at a radius close to the casing (around 95\% of blade height and called $r_{95}$ in the rest of the paper) are given in Figs. 6a and 6b for the baseline and the distortion case respectively. The maps are unwrapped to be represented in the $\theta-x$ axes, with $\theta$ the circumferential angle and $x$ the engine axis (flow direction is from bottom to top in the plots). The converged RANS results of the baseline case are duplicated to be easily compared with the results of the distortion case. For the latter, an instantaneous solution is plotted at a time such that the bottom is located at $\theta=-90^{\circ}$ and the top at $\theta=90^{\circ}$ (as in Fig. 3a). The same scale is used between both plots. The acceleration of the flow along the suction side of the blades leading to the formation of the shocks is clearly observed. Around the top of the nacelle $\left(\theta=90^{\circ}\right)$, the flow acceleration obtained with distortion is fairly close to the one observed for the baseline case. However, around the bottom of the nacelle $\left(\theta=-90^{\circ}\right)$, the flow is much more accelerated, which seems to modify the shape of the shocks. This flow acceleration can be related to the one observed on the distortion map shown in Fig. 3a.

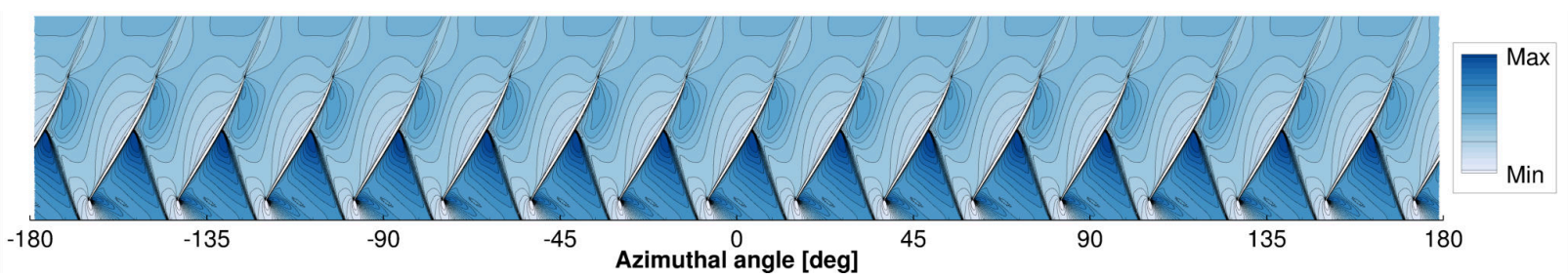

(a) Baseline case (duplicated field) - Relative Mach number.

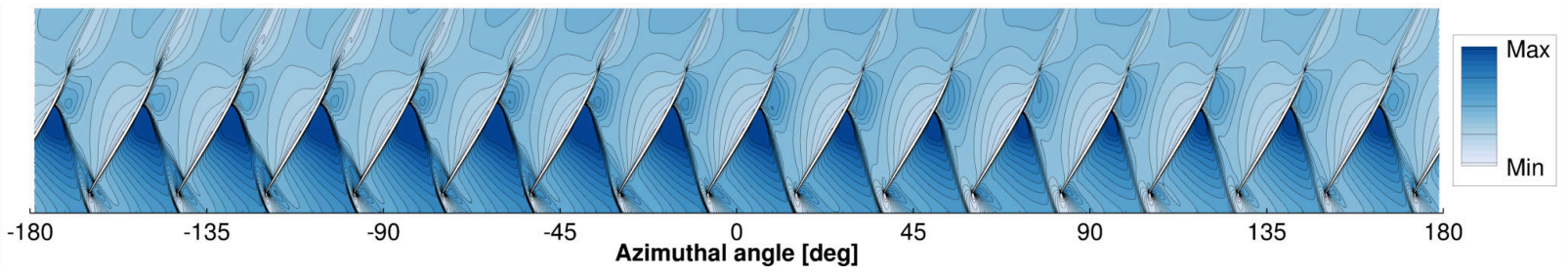

(b) Distortion case (instantaneous field) - Relative Mach number.

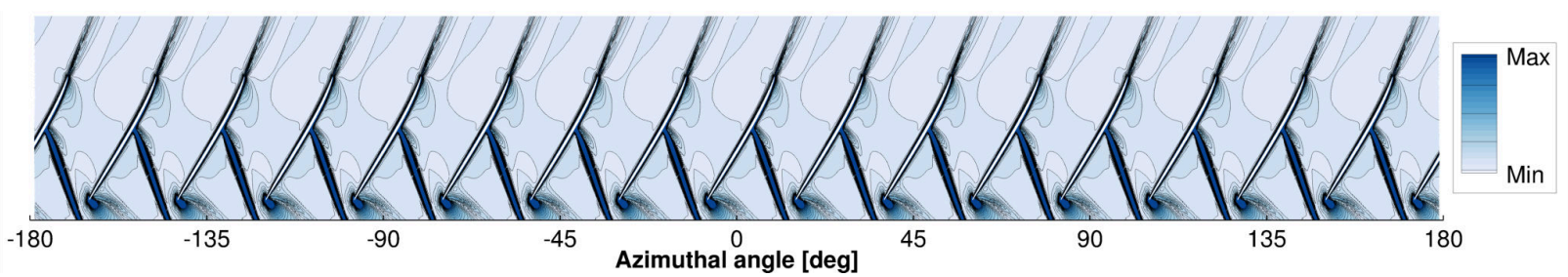

(c) Baseline case (duplicated field) - Density gradient magnitude.

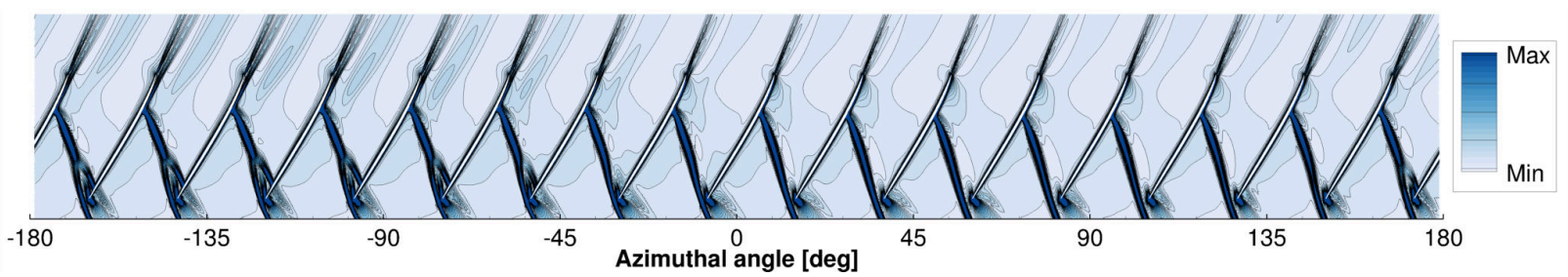

(d) Distortion case (instantaneous field) - Density gradient magnitude.

Fig. 6 Contour maps extracted at $r=r_{95}$.

Contour plots of density gradient magnitude are also given in Figs. 6c and 6d for both cases to better visualize the 
shocks. Again, the same scale is used between the two plots. The shocks around the top $\left(\theta=90^{\circ}\right)$ have a shape similar to the ones obtained without distortion. At the bottom $\left(\theta=-90^{\circ}\right)$, the flow acceleration makes the shocks appearing a bit closer to the trailing edge of the blades, which are therefore almost trapped inside the inter-blade channels.

\section{B. Shock Analysis}

For both cases, the flow fields are extracted at the same axial position in the vicinity of the fan to be injected into the CAA simulation. These flow fields contain the fan-blade shocks that will propagate inside the inlet duct and then radiate outside of the nacelle. They are analyzed here to provide a more detailed comparison between the shocks observed with and without distortion. The density fields obtained at this CFD/CAA interface location and expressed in the fixed frame (the one of the CAA simulation) are given in Fig. 7 For the baseline case, the field is duplicated over $360^{\circ}$ to make the comparison easier. The same scale is used between the plots and the same iteration is represented. The potentiel effect of the fan is observed around mid-span and the shocks emerge close to the tip. The shocks seem to be much stronger in the baseline case and a strong heterogeneity of the shocks is observed with distortion. In particular, the shocks in the bottom region are weaker than the ones in the top.

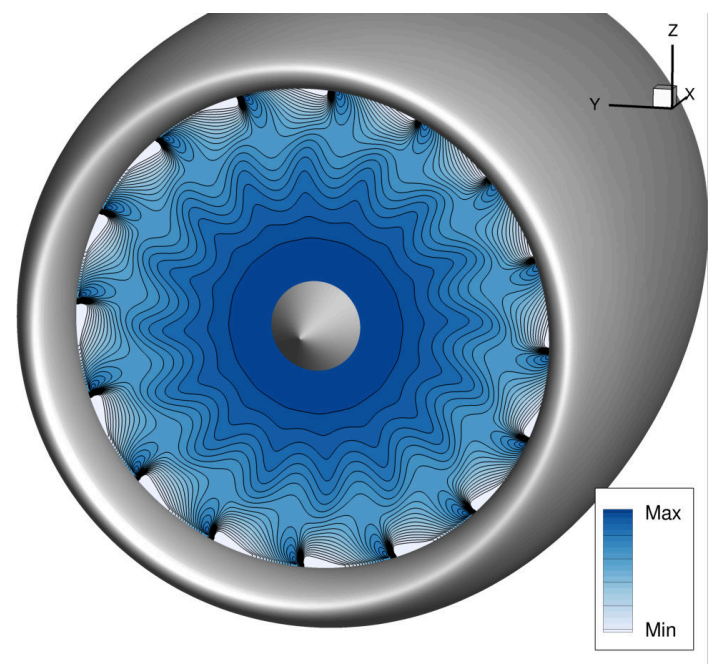

(a) Baseline case (duplicated field).

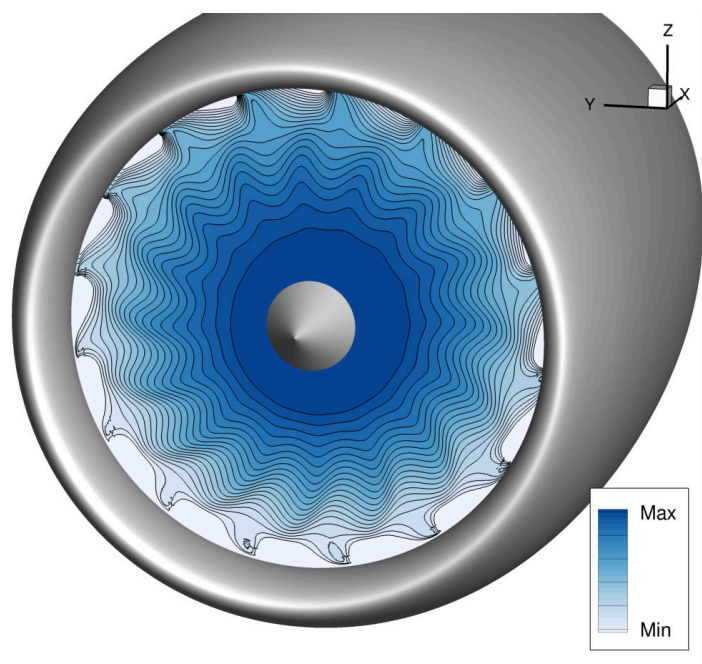

(b) Distortion case.

Fig. 7 Density contours at the CFD/CAA chaining interface.

This is further analyzed by extracting some probes over a full revolution from both simulations (note that the data injected in the CAA simulation is unsteady even for the baseline case since it is rotated at each time step to be expressed in the fixed frame). The static pressure signals obtained at 4 different azimuthal positions $\left(\theta=-180^{\circ}, \theta=-90^{\circ}, \theta=0^{\circ}\right.$ and $\theta=90^{\circ}$ ) and at $r=r_{95}$ are represented in Fig. 8a Only one curve is shown for the baseline case because it remains the same for the 4 positions (there is no time-shift since the probes are spaced by $90^{\circ}$, which is exactly the space between 4 blades). All curves are normalized by the mean value of the pressure signal obtained without distortion. $\mathrm{N}$-waves are observed and the amplitude of the shocks is effectively lower with distortion (almost two times lower at some positions). The strong heterogeneity between the different azimuthal positions in terms of amplitude is emphasized. A time-shift that can be linked to the different shock orientation is also present because of the distortion. However, the fluctuations seem to remain at the BPF and its harmonics even in the presence of distortion. This is evidenced in Fig. $8 \mathrm{~b}$ which shows the temporal Fourier transform of the precedent signals. Only the harmonics that are multiple of the number of blades (i.e. the BPF harmonics) emerge. This would have been different if some stagger variation was included between the blades as in [7].

The pressure field at the BPF over the whole CFD/CAA chaining interface is now plotted in Fig. 9, using the same scale for both cases. The higher levels are reached close to the casing where the shocks appear. Lower amplitudes are found when there is distortion and this can be related to weaker shocks. The heterogeneity is again observed with higher amplitudes in the top region. 


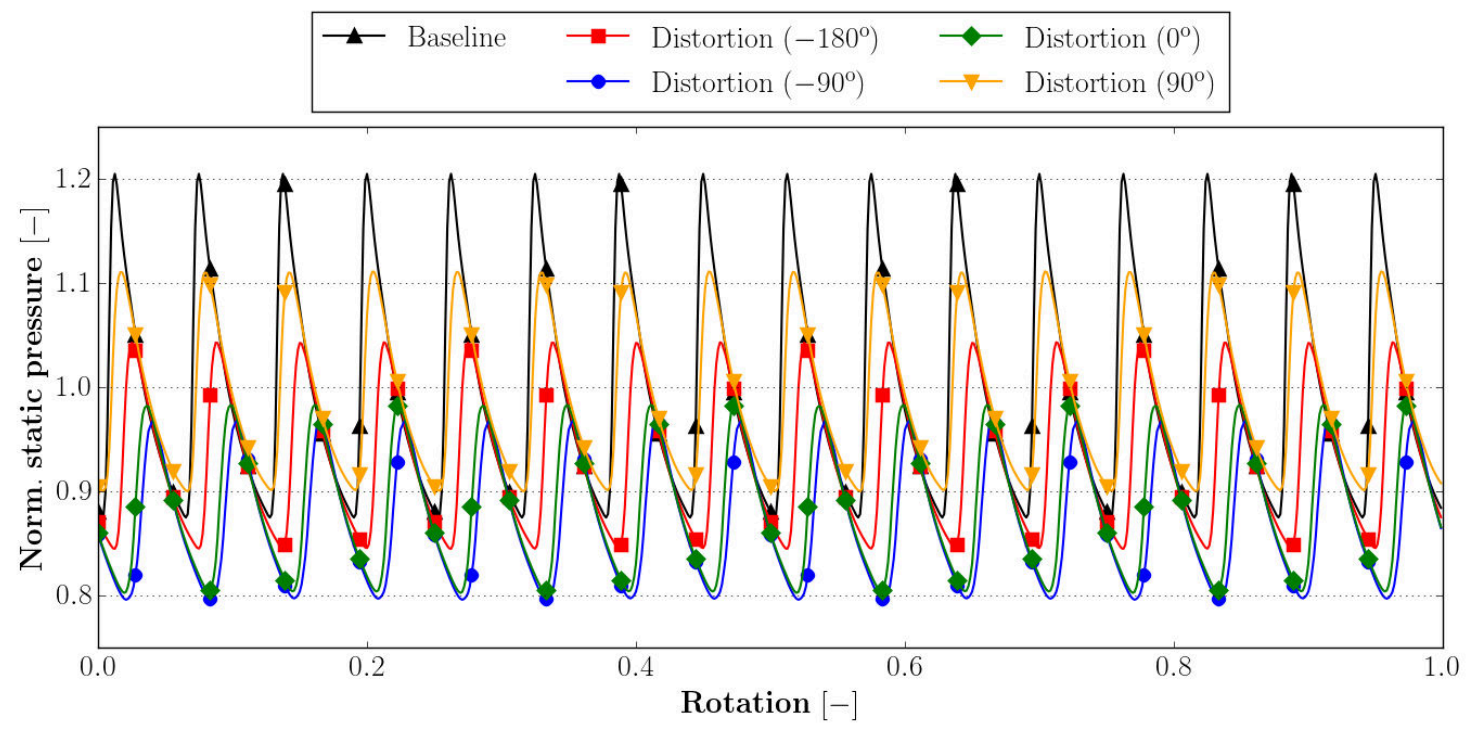

(a) Time signals.

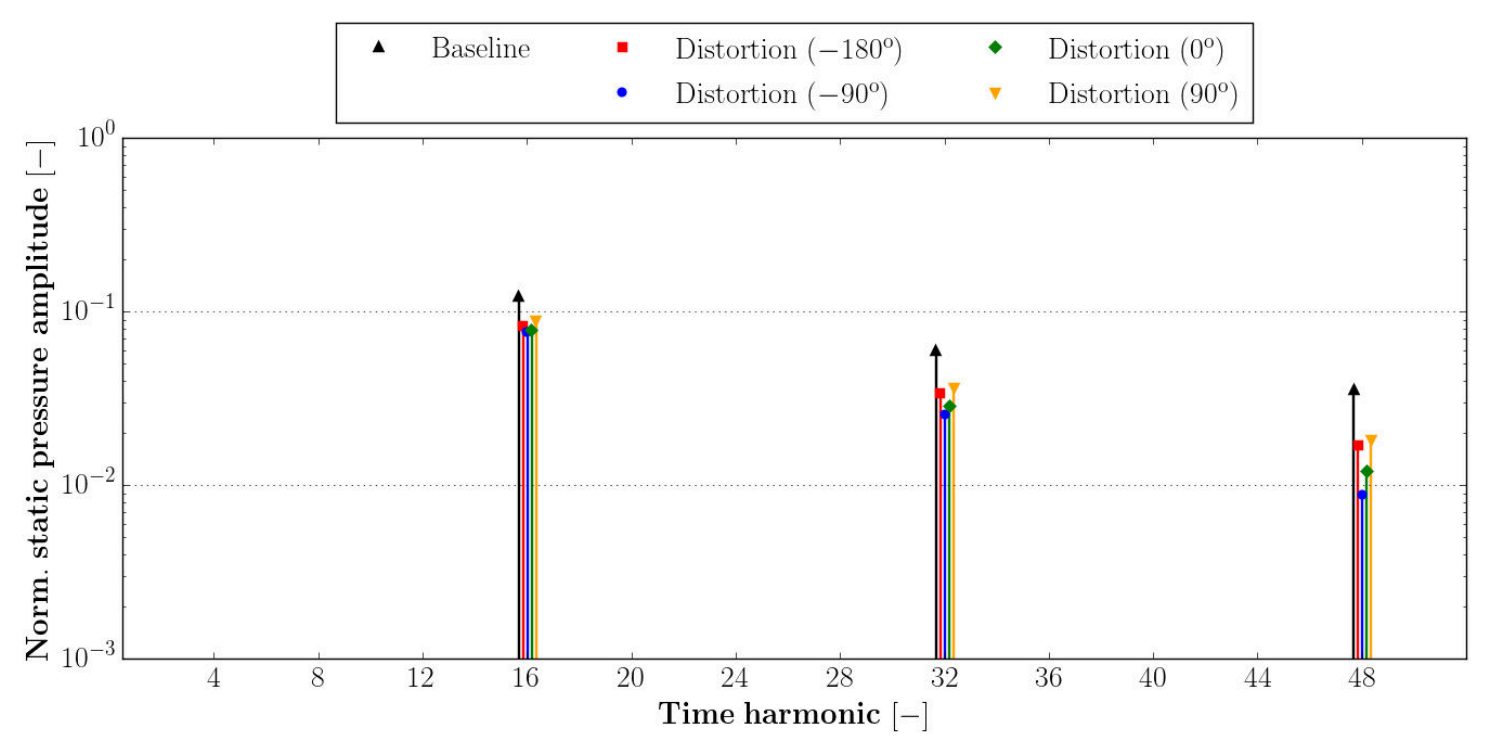

(b) Temporal Fourier transforms.

Fig. 8 Pressure time signal and Fourier transform at 4 different azimuthal positions and at $r=r_{95}$.

This heterogeneity is further analyzed in Fig. 10 where the azimuthal Fourier components computed at $r=r_{95}$ are given. Again, results are normalized by the mean value of the pressure signal obtained without distortion at this position. Only the rotor-locked mode $m=n B=16$ ( $n$ being the number of the BPF harmonic considered, here 1) appears for the baseline case. However, the distortion is responsible for the emergence of other modes close the rotor-locked one. Most of the signal is described by the rotor-locked mode and the distortion-rotor interaction modes $m=n B \pm 1$ and $m=n B \pm 2$ which are related to the harmonics of distortion shown in Fig. 3c Similar observations can be done at other BPFs. 


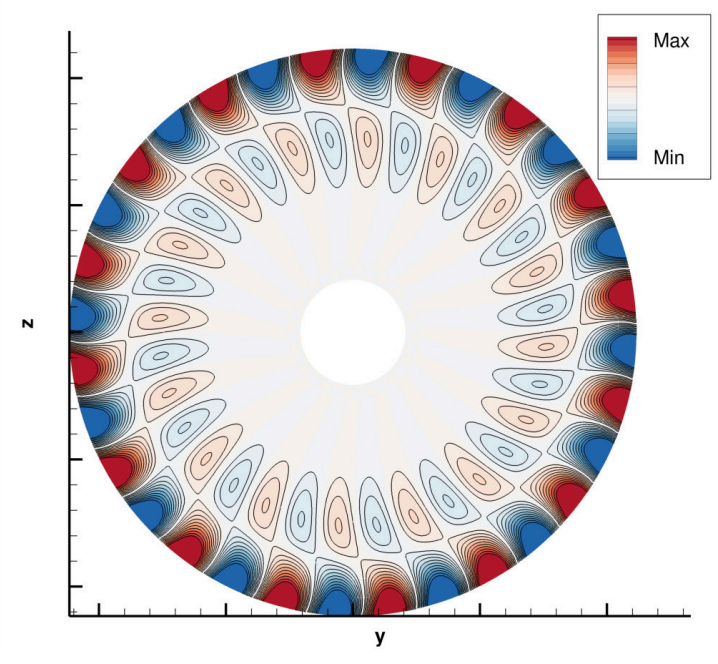

(a) Baseline case (duplicated field).

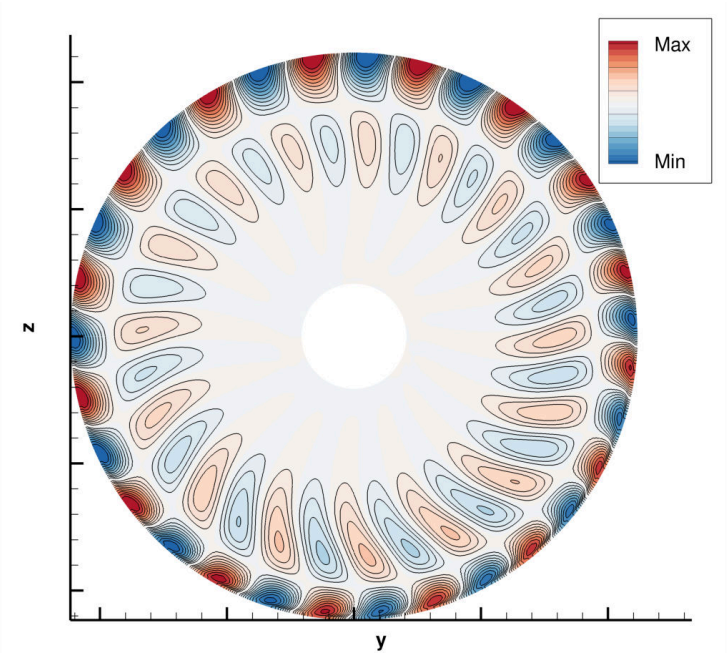

(b) Distortion case.

Fig. 9 Contour maps of pressure real part at the BPF on the CFD/CAA chaining interface.

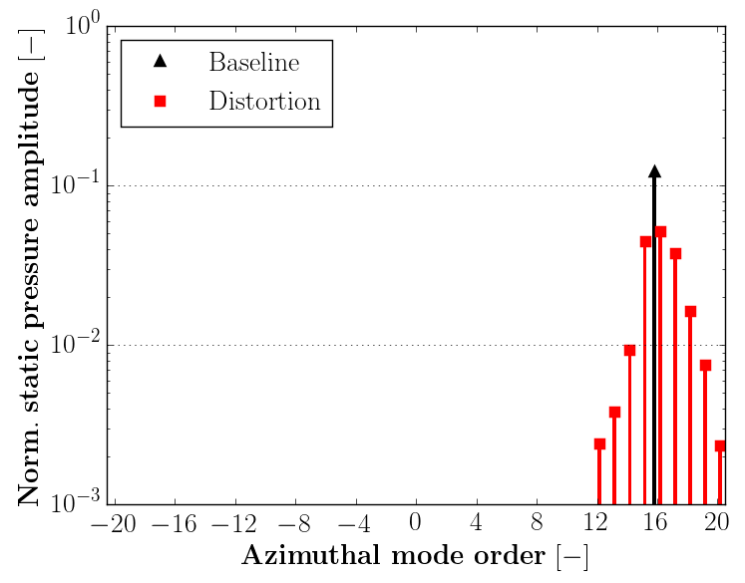

Fig. 10 Azimuthal mode distribution at $r=r_{95}$ at the BPF.

\section{Effects of Flow Distortion on Shockwave Radiation}

\section{A. Mean Flow inside and around the Nacelle}

The in-duct propagation of shocks and their radiation is now investigated. The mean flow obtained from CAA simulations is first analyzed in the nacelle in Fig. 11] where time-averaged axial Mach number contours are plotted for the baseline and distortion cases. Only one slice is shown for the baseline case (in Fig. 11a) since the mean flow is axisymmetric (note that the slice has been duplicated for comparison purposes). For the distortion case, two slices have been represented: one vertical slice at $y=0 \mathrm{~m}$ in Fig. $11 \mathrm{~b}$ (bottom is at $\theta=-90^{\circ}$ and top is at $\theta=90^{\circ}$ ) and one horizontal slice at $z=0 \mathrm{~m}$ in Fig. $11 \mathrm{c}$ (bottom is at $\theta=-180^{\circ}$ and top is at $\theta=0^{\circ}$ ). The same scale is used between all plots and the last contour level (dark red) corresponds to 1 . The flow acceleration around the casing is observed in all slices but is much more pronounced in the distortion case at the bottom of the nacelle $\left(\theta=-90^{\circ}\right)$ where a supersonic pocket is created. This is an effect of the flow incidence combined with the ultra short inlet duct. It is worth to note also that the mean flow is symmetric in the horizontal plane. 


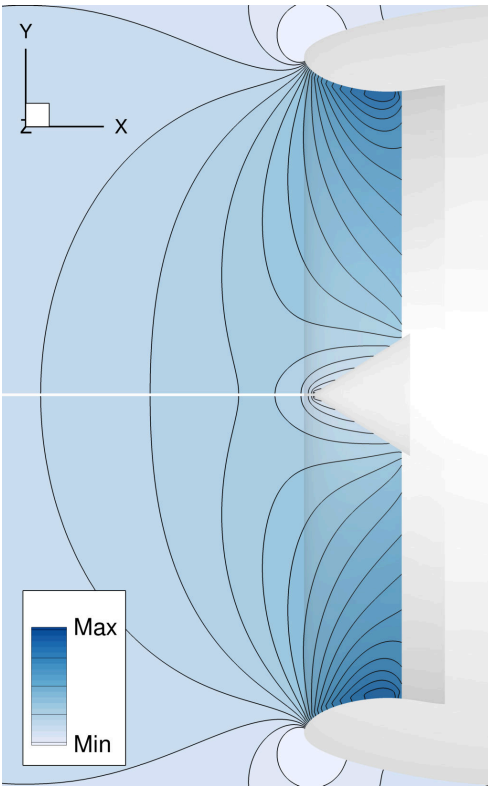

(a) Baseline case (duplicated field) - Symmetric slice.

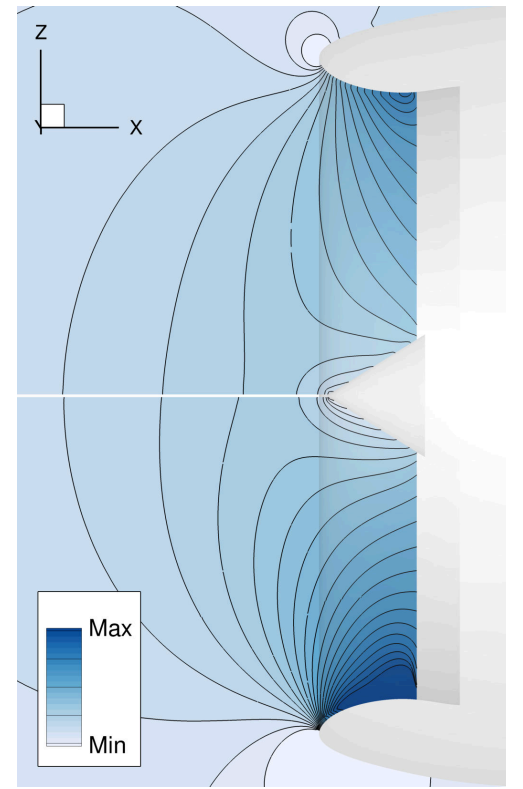

(b) Distortion case - Slice $y=0 \mathrm{~m}$.

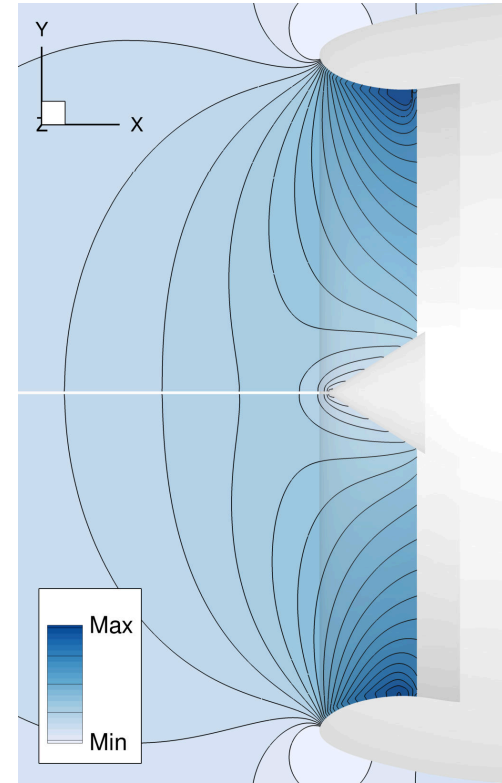

(c) Distortion case - Slice $z=0 \mathrm{~m}$.

Fig. 11 Contour maps of time-averaged axial Mach number on different slices.

\section{B. In-Duct Propagation of Shocks}

The focus is now put precisely on the propagation of shocks inside the inlet duct. This is done by plotting contour maps of density gradient magnitude at $r=r_{95}$ as in Figs. 6c and 6d, but from the CAA simulations instead of the CFD simulations. Results are given in Figs $12 \mathrm{a}$ and $12 \mathrm{~b}$ for the baseline and the distortion case respectively. The top of the plots corresponds to the position of the CFD/CAA interface (location right upstream of the fan) and the bottom of the plots to the exit of the nacelle. An important reduction of the shock strength during the in-duct propagation is observed for the baseline case and can be related to the strong reduction of Mach number in the nacelle. The distortion dramatically modifies the shock propagation in the inlet duct. The most important impact is observed in the bottom part of the nacelle (approximately from $\theta=-180^{\circ}$ to $\theta=0^{\circ}$ ) where the shocks completely disappear. The curve plotted in red is the isoline corresponding to an axial Mach number of 1 . It shows that this behaviour is due to the supersonic flow region with pushes back the fan-blade shocks. The shocks seem to exit the nacelle in the upper part of the nacelle only but with very different strengths and orientations.

These differences in shock orientations are responsible for differences in acoustic wave orientations. This is shown here at the BPF in Fig. 13 where pressure real part contours are plotted on the same slice and for both cases. It can be observed that the pressure waves propagate with the shocks and exit the nacelle with an orientation that depends on the circumferential position. Between $\theta=0^{\circ}$ and $\theta=45^{\circ}$, the waves are almost perpendicular to the nacelle axis while they are almost parallel to it between $\theta=135^{\circ}$ and $\theta=180^{\circ}$.

The high heterogeneity of the acoustic field during the in-duct propagation can be expressed in terms of azimuthal modes. Azimuthal profiles of the pressure field at the BPF are extracted at $r=r_{95}$ and at three axial positions (one close to the fan, one in the middle of the inlet duct, and one close to the nacelle exit) and a spatial Fourier transform is computed to determine the dominant modes. Results are presented in Fig. 14for both baseline and distortion cases. They are normalized by the mean value of the pressure obtained without distortion at $r=r_{95}$ and at the axial position close to the fan. For the baseline case, only the rotor-locked mode $m=n B=16$ appears along the inlet. The presence of distortion introduces a lot of new azimuthal modes with decreasing amplitudes when going farther from the rotor-locked mode. Close to the fan, most of the signal is described by the rotor-locked mode and the distortion-rotor interaction modes $m=n B \pm 1$ and $m=n B \pm 2$ as discussed before. But the signal is spread over more and more modes along the propagation such that almost all modes between -20 and 20 are within one order of magnitude close to the nacelle exit. This is partly due to the scattering of the modes over neighbour modes because of the distortion but it is also a 


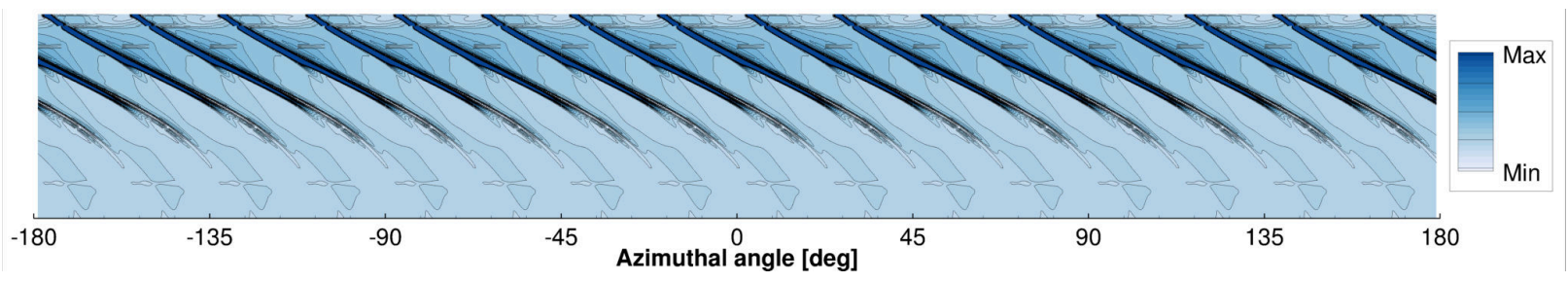

(a) Baseline case (duplicated field).

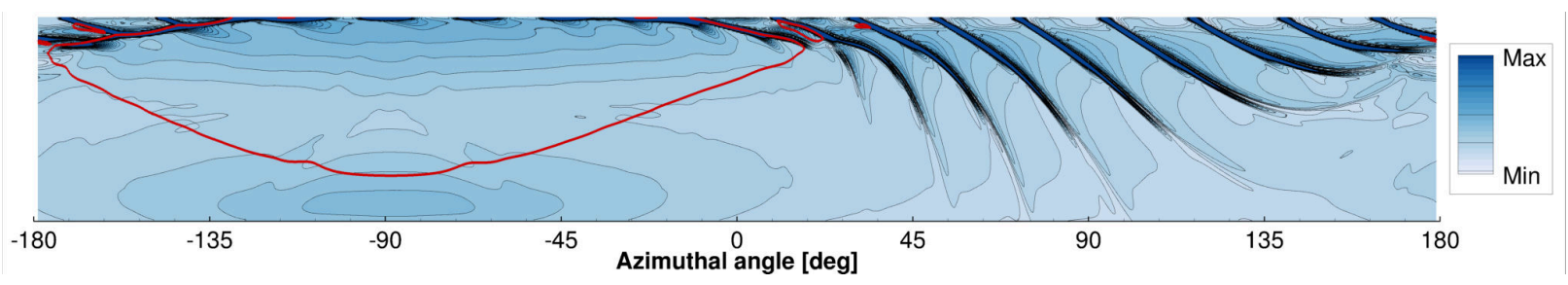

(b) Distortion case.

Fig. 12 Contour maps of instantaneous density gradient magnitude and sonic isoline in red at $r=r_{95}$.

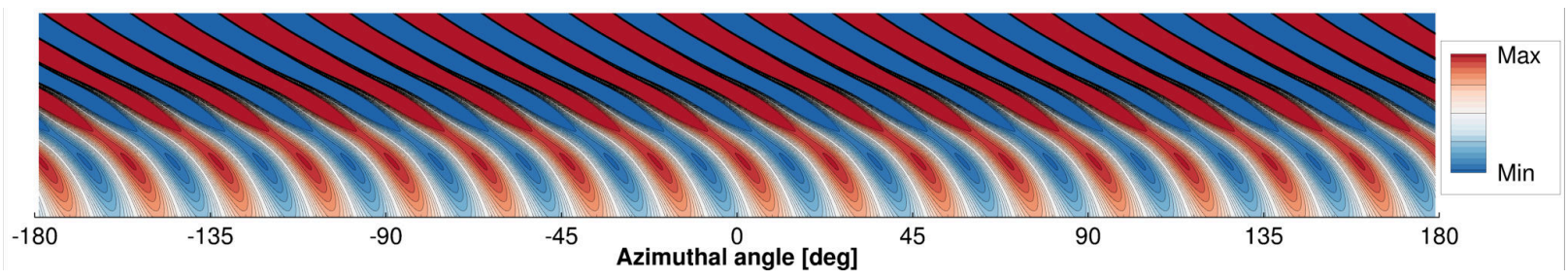

(a) Baseline case (duplicated field).

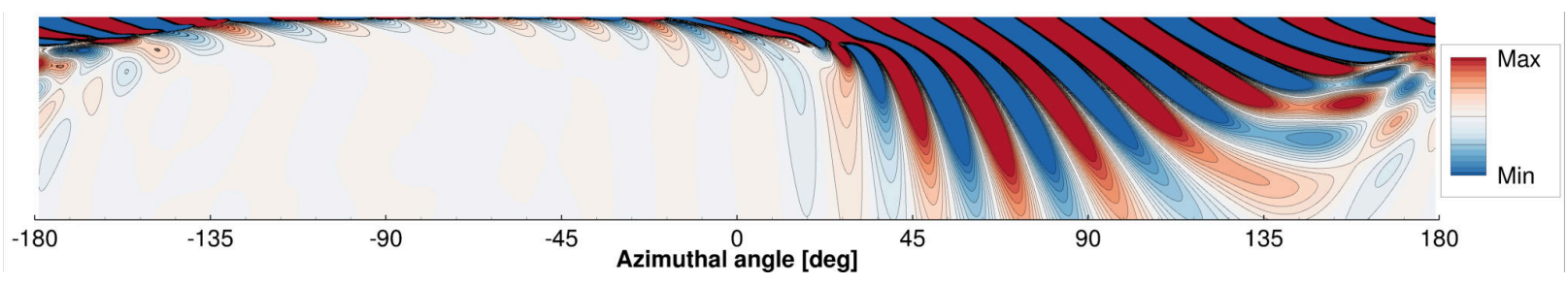

(b) Distortion case.

Fig. 13 Contour maps of pressure real part at $r=r_{95}$ at the BPF.

consequence of the blockage of shocks in the bottom part of the nacelle which breaks down the rotating mode analysis.

\section{Near-Field Radiation of Shocks}

The near-field acoustic radiation is now investigated in Figs. 15, 16 and 17 where contours maps of pressure real part in the vicinity of the nacelle inlet are plotted at BPF1, BPF2, and BPF3 respectively. For each BPF, only one slice is represented for the baseline case because of its symmetry while two slices are plotted for the distortion such as in Fig. 11. one vertical slice at $y=0 \mathrm{~m}$ (bottom is at $\theta=-90^{\circ}$ and top is at $\theta=90^{\circ}$ ) and one horizontal slice at $z=0 \mathrm{~m}$ (bottom is at $\theta=-180^{\circ}$ and top is at $\theta=0^{\circ}$ ). For all BPFs and without distortion, the radiation is oriented to the sides (i.e. far from the axis) because of the relative high order of the rotor-locked mode which is the only existing mode. The waves propagate over smaller distance with increasing BPF because of the stretching zone. In the presence of distortion, the radiation is strongly heterogeneous in both the vertical plane and the horizontal one. The heterogeneity in the vertical plane is first discussed. Because of the blockage of shocks in the bottom part of the nacelle, the radiation is clearly oriented to the top, with very low levels obtained towards the ground. The pressure waves that exit the nacelle 


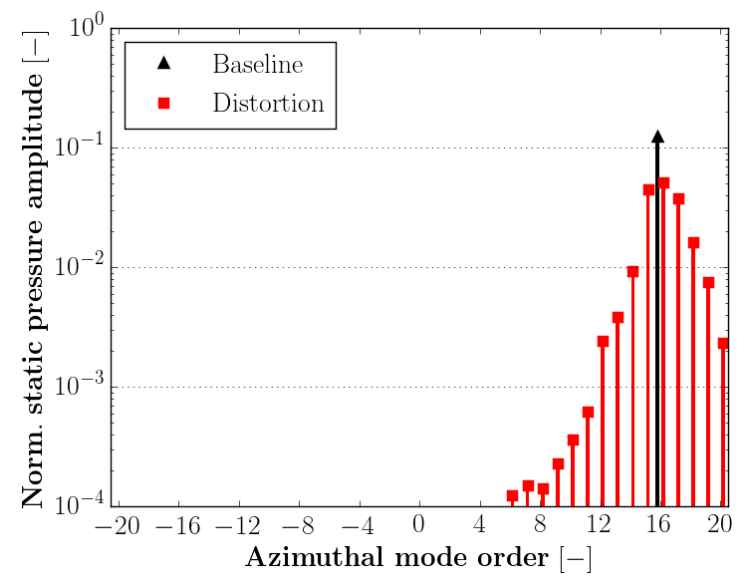

(a) Position close to the fan.

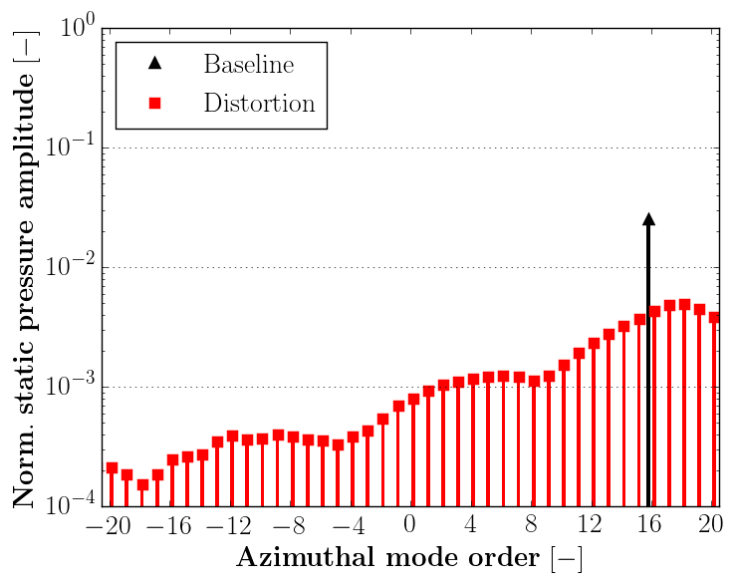

(b) Position in the middle of the inlet duct.

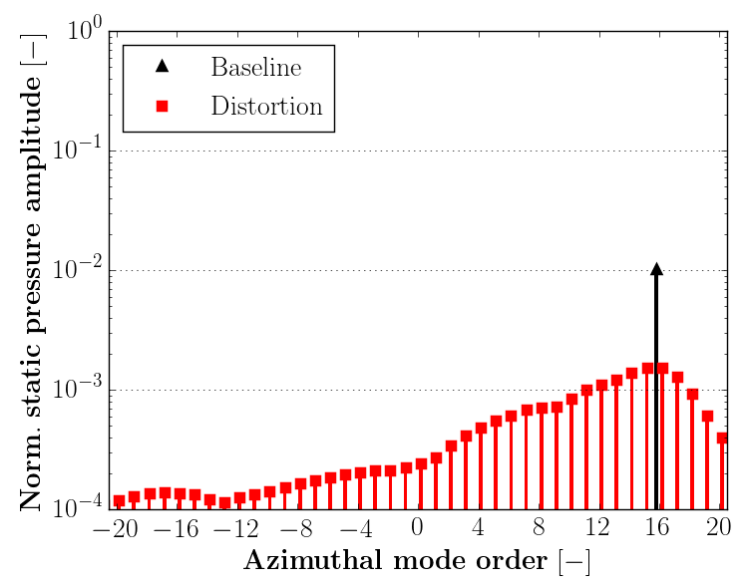

(c) Position close to the nacelle exit.

Fig. 14 Azimuthal mode distribution at the BPF at different axial positions on a radial slice (around 95\% of blade height).

from its top are less oriented towards the sky than in the baseline case because of the presence of lower order modes. Interferences in the radial direction also occur which indicates the presence of radial modes of order higher than 1 . The radiation is also heterogeneous in the horizontal plane, which is less expected given the symmetry of the mean flow on this plane (see Fig. 11c). This is caused by the different orientations of the shocks that exit the nacelle shown in Fig. $12 \mathrm{~b}$ In the bottom of the corresponding plots i.e. at $\theta=-180^{\circ} / 180^{\circ}$, the pressure waves were shown to exit the nacelle almost parallel to its axis (see Fig. 13b). This gives rise to a radiation oriented straight upwards, with significant levels on both the side and the axis. However, in the top part of the plots i.e. at $\theta=0^{\circ}$, the direction of propagation of pressure waves was shown to be almost perpendicular to the nacelle axis (see Fig. 13b). The near-field radiation is therefore more oriented towards the side at this position.

\section{Conclusion}

Shockwave generation and radiation from an UHBR engine with inflow distortion has been investigated using a CFD/CAA chaining method. The shocks are extracted from a CFD simulation and are injected in the CAA domain in terms of conservative variables using a non-reflecting boundary condition. The CAA is based on the non-linearized Euler equations which allows to study the shock generation and the shock propagation mechanisms separately by putting the CFD/CAA interface close to the fan where the flow is highly non-linear. Inlet or liner (in the future) design 


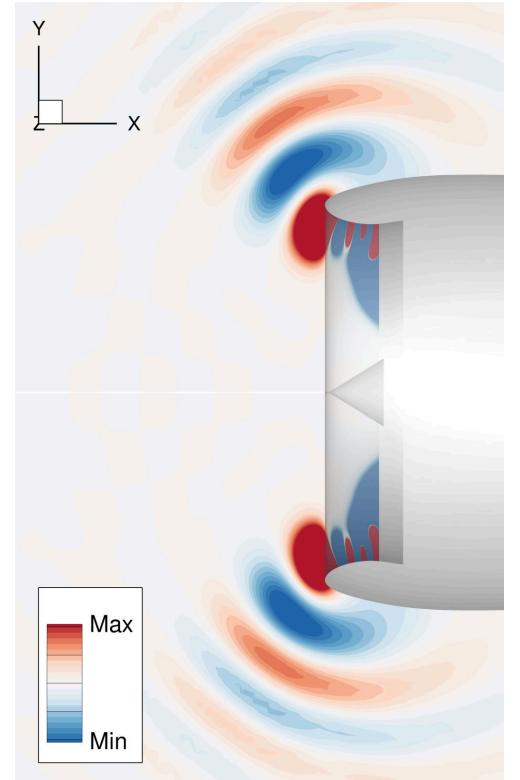

(a) Baseline case (duplicated field) - Symmetric slice.

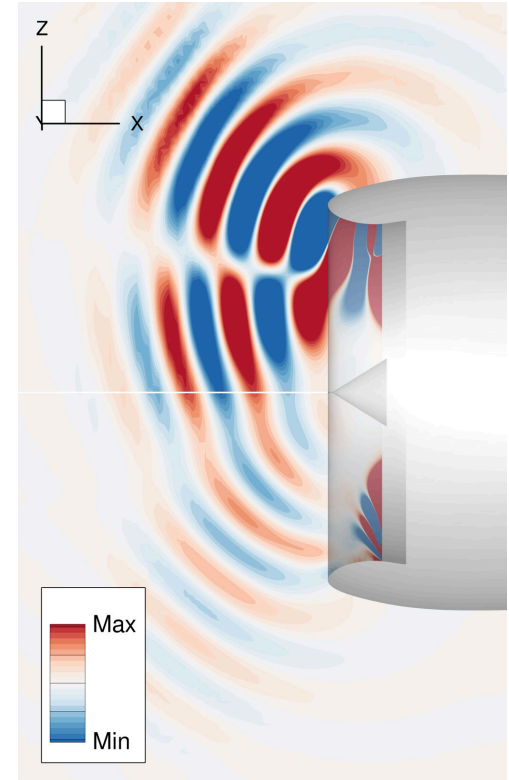

(b) Distortion case - Slice $y=0 \mathrm{~m}$.

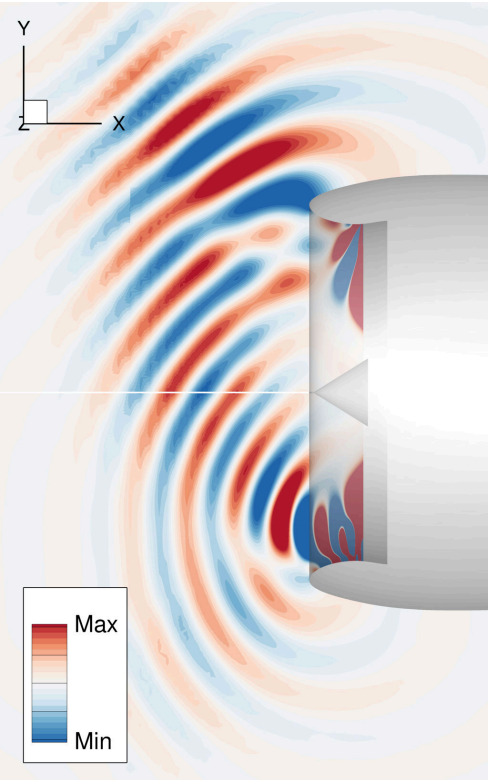

(c) Distortion case - Slice $z=0 \mathrm{~m}$

Fig. 15 Contour maps of pressure real part on different slices in the near-field at BPF1.

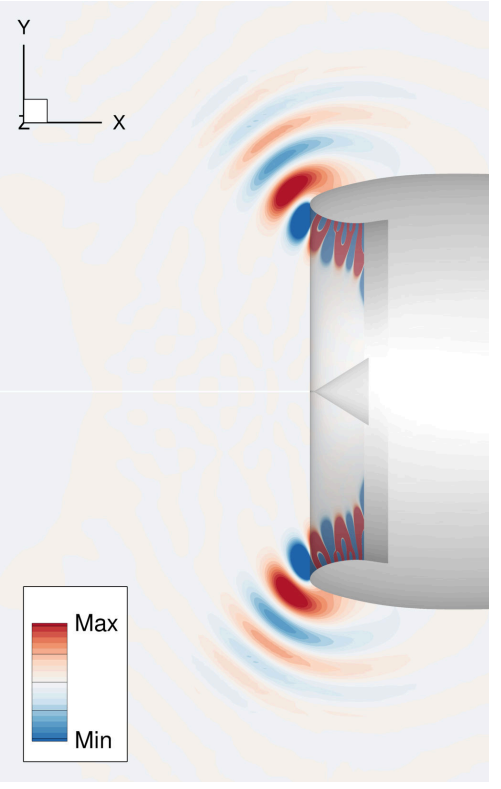

(a) Baseline case (duplicated field) - Symmetric slice.

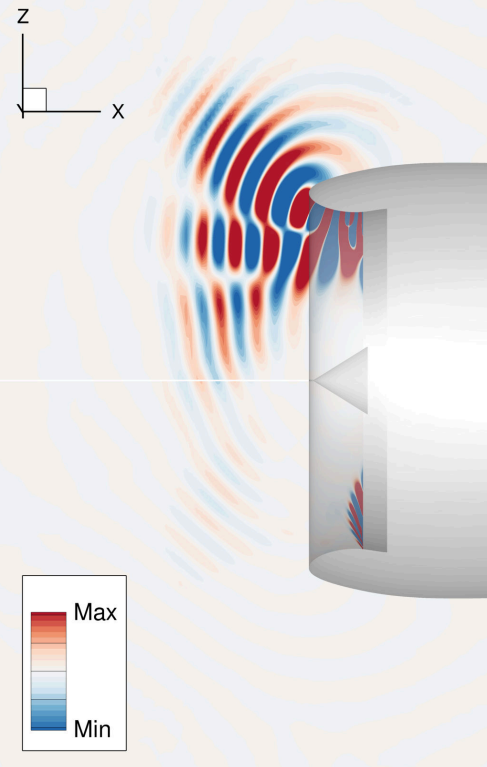

(b) Distortion case - Slice $y=0 \mathrm{~m}$.

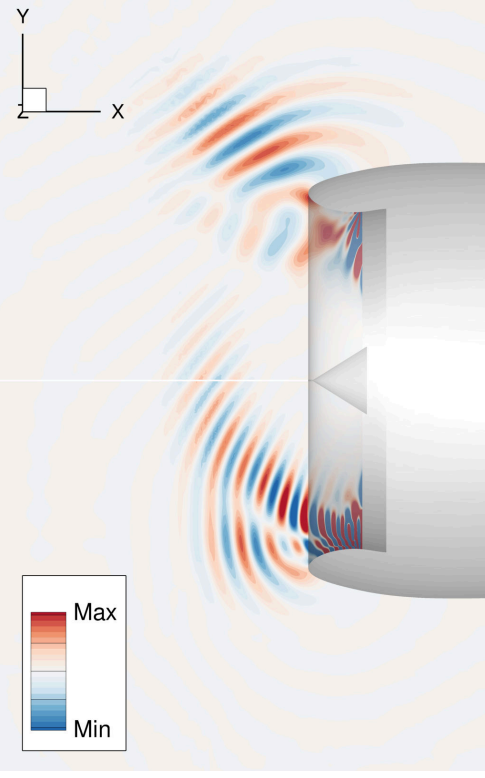

(c) Distortion case - Slice $z=0 \mathrm{~m}$.

Fig. 16 Contour maps of pressure real part on different slices in the near-field at BPF2.

optimization could therefore be done in the presence of a realistic source. The chaining method is shown to behave correctly on a baseline case without distortion and is then applied to the case with distortion.

Results on both generation and radiation have been provided and the effects of distortion were highlighted by 


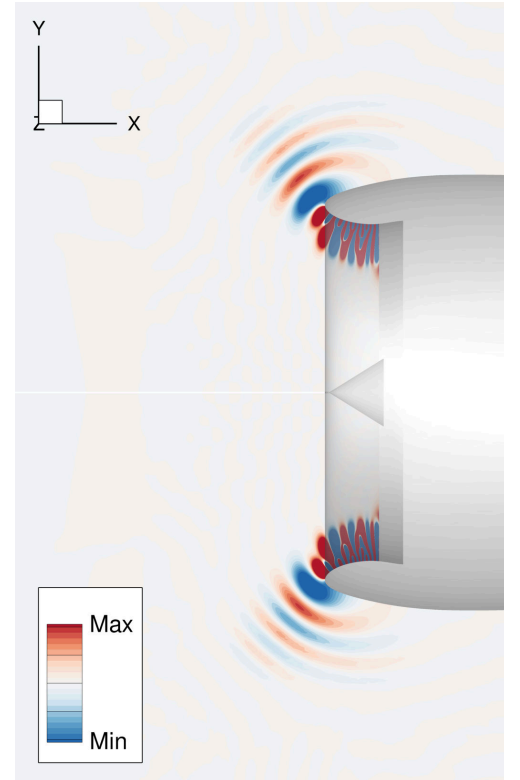

(a) Baseline case (duplicated field) - Symmetric slice.

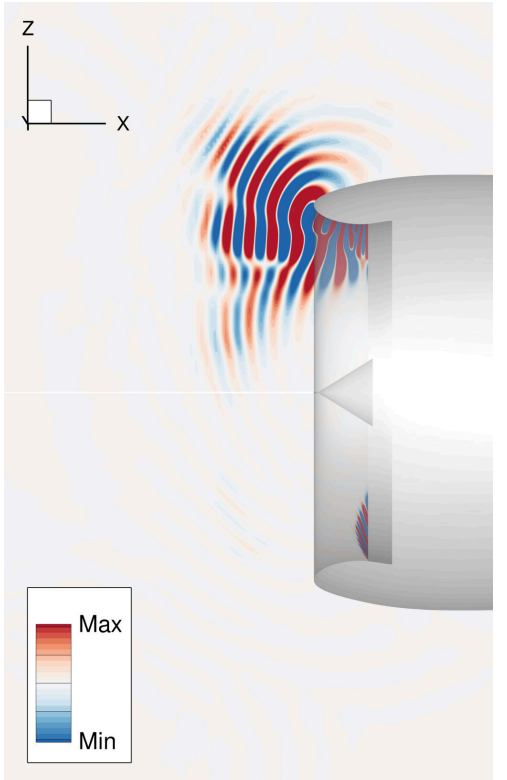

(b) Distortion case - Slice $y=0 \mathrm{~m}$.

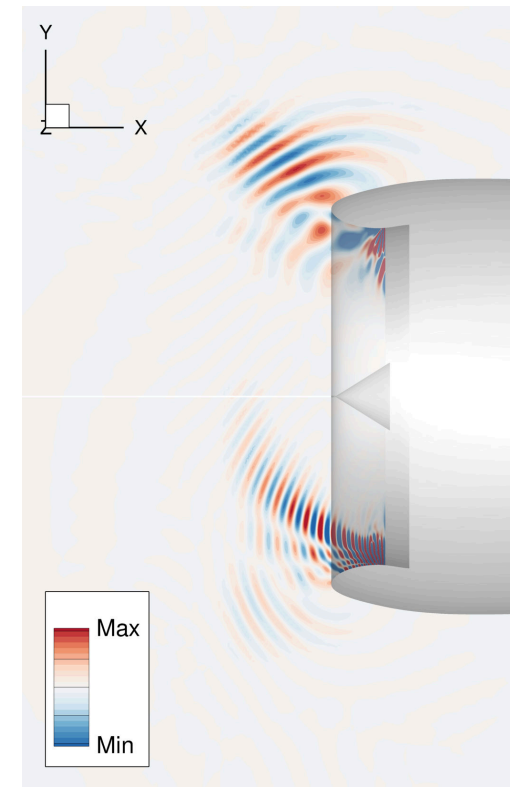

(c) Distortion case - Slice $z=0 \mathrm{~m}$.

Fig. 17 Contour maps of pressure real part on different slices in the near-field at BPF3.

comparing both cases. It is shown that the distortion strongly influences the generation of shocks in terms of strength and position. In the vicinity of the fan, the pressure field at the BPFs is no more described by the rotor-locked mode since other neighbour modes appear. The number of contributing modes increases while the shocks propagate in the inlet duct. A very important feature of the studied configuration is the presence of a supersonic flow region in the bottom part of the nacelle induced by the flow incidence. This supersonic pocket blocks the shocks in the lower half of the nacelle and the acoustic radiation is found to be strongly oriented towards the sky. It is also shown that the radiation in the other directions was highly heterogeneous because of the different orientations of the shocks that exit the nacelle.

\section{Acknowledgments}

ONERA carried out this study in the framework of the ASPIRE project in close cooperation with partners Airbus, NLR, and DLR. It has received funding from the Clean Sky 2 Joint Undertaking under the European Union's H2020 program (grant agreement no. 681856).

\section{References}

[1] Winkler, J., Reimann, C. A., Reba, R. A., and Gilson, J., “Turbofan Inlet Distortion Noise Prediction with a Hybrid CFD-CAA Approach," 20th AIAA/CEAS Aeroacoustics Conference, 2014.

[2] Doherty, M., and Namgoong, H., "Impact of Turbofan Intake Distortion on Fan Noise Propagation and Generation," 22nd AIAA/CEAS Aeroacoustics Conference, 2016.

[3] Winkler, J., Reimann, C. A., Gumke, C. D., Ali, A. A., and Reba, R. A., "Inlet and Aft Tonal Noise Predictions of a Full-Scale Turbofan Engine with Bifurcation and Inlet Distortion,” 23rd AIAA/CEAS Aeroacoustics Conference, 2017.

[4] Daroukh, M., Moreau, S., Gourdain, N., Boussuge, J.-F., and Sensiau, C., "Effect of Distortion on Turbofan Tonal Noise at Cutback with Hybrid Methods," International Journal of Turbomachinery, Propulsion and Power, Vol. 2, No. 3, 2017 , p. 16.

[5] Daroukh, M., Moreau, S., Gourdain, N., Boussuge, J.-F., and Sensiau, C., "Tonal Noise Prediction of a Modern Turbofan Engine With Large Upstream and Downstream Distortion," Journal of Turbomachinery, Vol. 141, No. 2, 2019 , p. 021010. 
[6] Milidonis, K. F., Hynes, T., Doherty, M., and Namgoong, H., "The Effect of Steady Intake Distortion on Fan MPT Noise Under Sideline Flight Conditions," 2018 AIAA/CEAS Aeroacoustics Conference, 2018.

[7] Laban, M., Kok, J. C., and Brouwer, H. H., "CFD/CAA Analysis of UHBR Engine Tonal Noise,” 2018 AIAA/CEAS Aeroacoustics Conference, 2018.

[8] Guérin, S., and Holewa, A., "Fan tonal noise from aircraft aeroengines with short intake: A study at approach," International Journal of Aeroacoustics, Vol. 17, No. 6-8, 2018, pp. 600-623.

[9] Thisse, J., "Prévision du bruit d'onde de choc d'un turboréacteur en régime transsonique par des méthodes analytiques et numériques," Ph.D. thesis, Ecole Nationale Supérieure d'Arts et Métiers, 2015.

[10] Thisse, J., Polacsek, C., Mayeur, J., Khelladi, S., Gloerfelt, X., and Lafitte, A., "Numerical Simulations of Shock-Wave Propagation in Turbofan Intakes," 22nd AIAA/CEAS Aeroacoustics Conference, 2016.

[11] Lewy, S., Polacsek, C., and Barrier, R., "Analytical and numerical prediction of harmonic sound power in the inlet of aero-engines with emphasis on transonic rotation speeds," Journal of Sound and Vibration, Vol. 333, No. 26, 2014, pp. $7165-7182$.

[12] Cambier, L., Heib, S., and Plot, S., "The Onera elsA CFD software: input from research and feedback from industry," Mechanics \& Industry, Vol. 14, No. 3, 2013, pp. 159-174. 